\title{
Synthesis of ZnO Nanowires via Hotwire Thermal Evaporation of Brass (CuZn) Assisted by Vapor Phase Transport of Methanol
}

\author{
Tamil Many K. Thandavan, ${ }^{1}$ Siti Meriam Abdul Gani, ${ }^{2}$ \\ Chiow San Wong, ${ }^{1}$ and Roslan Md Nor ${ }^{1}$ \\ ${ }^{1}$ Plasma Technology Research Centre, Department of Physics, University of Malaya, Lembah Pantai, \\ 50603 Kuala Lumpur, Malaysia \\ ${ }^{2}$ Low Dimensional Material Research Centre, Department of Physics, University of Malaya, Lembah Pantai, \\ 50603 Kuala Lumpur, Malaysia \\ Correspondence should be addressed to Tamil Many K. Thandavan; tamilmanykthandavan@gmail.com \\ and Roslan Md Nor; rmdnor@um.edu.my
}

Received 20 March 2014; Revised 14 May 2014; Accepted 15 May 2014; Published 18 June 2014

Academic Editor: Benxia Li

Copyright (c) 2014 Tamil Many K. Thandavan et al. This is an open access article distributed under the Creative Commons Attribution License, which permits unrestricted use, distribution, and reproduction in any medium, provided the original work is properly cited.

\begin{abstract}
Zinc oxide $(\mathrm{ZnO})$ nanowires (NWs) were synthesized using vapor phase transport (VPT) and thermal evaporation of Zn from CuZn. Time dependence of $\mathrm{ZnO}$ NWs growth was investigated for 5, 10, 15, 20, 25, and 30 minutes. Significant changes were observed from the field electron scanning electron microscopy (FESEM) images as well as from the X-ray diffraction (XRD) profile. The photoluminescence (PL) profile was attributed to the contribution of oxygen vacancy, zinc interstitials, and hydrogen defects in the ZnO NWs. Raman scattering results show a significant peak at $143 \mathrm{~cm}^{-1}$ and possible functionalization on the wall of $\mathrm{ZnO}$ NWs. Growth of ZnO NWs in (0002) with an estimated distance between adjacent lattice planes $0.26 \mathrm{~nm}$ was determined from transmission electron microscopy (TEM) analysis.
\end{abstract}

\section{Introduction}

$\mathrm{ZnO}$ is a unique material with a wide band gap of $3.37 \mathrm{eV}$ and a large exciton binding energy of $60 \mathrm{meV}$ at room temperature. These properties and the development of nanosized $\mathrm{ZnO}$ have attracted much attention both in basic science and industrial applications [1]. Thus, many efforts have been employed for achieving $\mathrm{ZnO}$ in one-dimensional (1D) nanostructures as nanotubes [2], nanowires [3], nanorods $[4,5]$, nanobelts [6], nanocables [7], and nanoribbons [8] using physical evaporization [9], chemical vapor deposition [10, 11], solvothermal [12], and carbothermal method [13] on different substrate materials. However, the growth techniques are ranged from low temperature wet chemical growth technique to metal organic chemical vapor deposition (MOCVD) technique [14] at temperatures above $1000^{\circ} \mathrm{C}$. The MOCVD technique has led to high quality growth of columnar structured film with higher growth rate but not straight forward to fabricate smooth $\mathrm{ZnO}$ thin film on flat surfaces. Indeed, growing $\mathrm{ZnO}$ film homoepitaxially on $\mathrm{ZnO}$ substrate using vapor phase transport (VPT) method [15] was favored earlier but seems to be far from cost-effective and high volume production. Nevertheless, VPT is still a suitable technique to grow nanoscale $\mathrm{ZnO} \mathrm{NWs}$ in bulk, nanorods, and thin film effectively since this method allows NWs to be grown directly from substrate and does not require any catalyst or seed layers to promote the growth of $\mathrm{ZnO}$ NWs [16]. Apart from this, VPT enables the control of morphology and size of the nanostructures as parameters like reaction time and temperature are adjustable. Yu et al. have reported that reaction time less than 2 hours has produced high quality $\mathrm{ZnO} \mathrm{NWs}$ via VPT compared to organic solution based chemistry which takes about 2 to $12 \mathrm{~h}$ [16]. Earlier, Zhu et al [17]. used VPT method and detailed a comparative study on $\mathrm{ZnO}$ NWs growth using different metal catalyst and different substrate material. This has imparted 


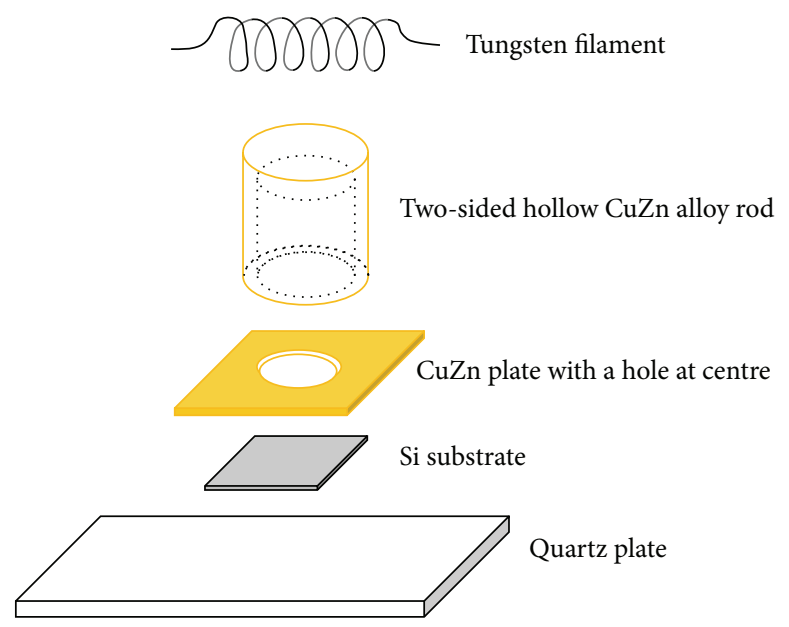

Figure 1: Illustration of experimental setup in order from bottom; quartz plate, Si substrate, CuZn plate, two-sided hollow CuZn metal rod, and tungsten hotwire in a vacuum chamber.

one-dimensional $\mathrm{ZnO}$ nanostructures with different range of diameters, densities, and aspect ratios [17]. In this study we are reporting a technique that consumes deposition period and is feasible in growing $\mathrm{ZnO}$ at suitable temperature on silicon substrate. This involves the combination of VPT of methanol and thermal evaporation of $\mathrm{CuZn}$ to obtain large area of deposition with reduced time of reaction. The use of $\mathrm{CuZn}$ as the $\mathrm{Zn}$ source is to benefit from a solid source with the potential to be fashioned to produce patterned deposition. The technique described here is significantly different from other reported techniques of the synthesis of $\mathrm{ZnO}$ nanostructures directly on $\mathrm{Zn}$ substrates or using mixtures of $\mathrm{ZnO}$ and carbon powders. With CuZn, the dezincification process [18] where $\mathrm{Zn}$ segregates to the surface of $\mathrm{CuZn}$ when heated to below its melting point of $914^{\circ} \mathrm{C}$ is utilized. The $\mathrm{Zn}$ droplets formed during the dezincification process are transported to the substrate surface under gas flow to be oxidized to $\mathrm{ZnO}$.

\section{Experimental}

The ZnO NWs were grown on Si (001) substrate. CuZn alloy was used as $\mathrm{Zn}$ source, whereas methanol was used as source of oxygen in this work. CuZn alloy of 55.11, 37.91, 3.84 , and 3.13 weight $\%$ for $\mathrm{Cu}, \mathrm{Zn}, \mathrm{Al}$, and $\mathrm{Pb}$, respectively, was verified by EDAX measurement and was used as $\mathrm{Zn}$ source. Mirror finished Si (001) wafer was used as a substrate for the growth of $\mathrm{ZnO}$ NWs. The Si wafer was cut into chips about 1.5 by $1.5 \mathrm{~cm}$ and the oxide layer removed using hydrofluoric acid (HF) solution. Then the Si chips were cleaned ultrasonically about 30 minutes in acetone solution. The cleaned Si chips were rinsed in deionized (DI) water and let to dry in desiccators at room temperature to remove moisture content on the Si substrate. The dried Si chip was placed on a quartz slide before being transferred into the vacuum chamber. A CuZn alloy plate thickness of $0.5 \mathrm{~mm}$ with dimension of 2.3 by $2.3 \mathrm{~cm}$ and $0.5 \mathrm{~cm}$ diameter hole in middle was cleaned ultrasonically in acetone bath and rinsed with DI water before placing it on the Si chip. A two-sided hollow CuZn rod was placed on the Si chip to cover the whole surface of Si substrate. The illustration of experimental setup is shown in Figure 1.

Argon (Ar) was flowed at $100 \mathrm{sccm}$ through mixture of methanol and acetone solution to allow methanol vapor to be transported into the deposition chamber. The gas tubing systems were filled with drying agent and potassium silicates in order to allow dried methanol and Ar flow into the deposition chamber. This methanol vapor underwent thermal dissociation under tungsten hotwire which was heated to $1800^{\circ} \mathrm{C}$. Copper $(\mathrm{Cu})$ in the $\mathrm{CuZn}$ did not undergo thermal evaporation due to its higher melting point compared to the operating temperature. $\mathrm{Zn}$ in CuZn was thermally evaporated at temperature greater than $395^{\circ} \mathrm{C}$. The vaporized $\mathrm{Zn}$ and methanol particles were condensed on $\mathrm{Si}$ substrate which was monitored at temperature of $800^{\circ} \mathrm{C}$. The deposition period was prolonged for 30 minutes. At the end of the 30th minute the methanol transportation was halted and the hotwire was switched off but continuous flow of Ar at $100 \mathrm{sccm}$ without flowing through the mixture of methanol and acetone solution was maintained until the temperature of substrate dropped to room temperature. The influence of growth time dependent of $\mathrm{ZnO}$ NWs was investigated by varying the growth time periods to $25,20,15,10$, and 5 minutes.

\section{Results and Discussions}

3.1. FESEM. Figure 2 shows the images of $\mathrm{ZnO}$ NWs prepared at various growth times of 5, 10, 15, 20, 25, and 30 minutes. Significant changes in the morphology and structure of $\mathrm{ZnO}$ NWs are identical as the growth time was varied. Growth of hexagonal nanorods and NWs is observable as displayed in Figure 2. The stem can be attributed to hexagonal wurtzite $\mathrm{ZnO}$ structure which stacks up to a button shaped $\mathrm{ZnO}$. 


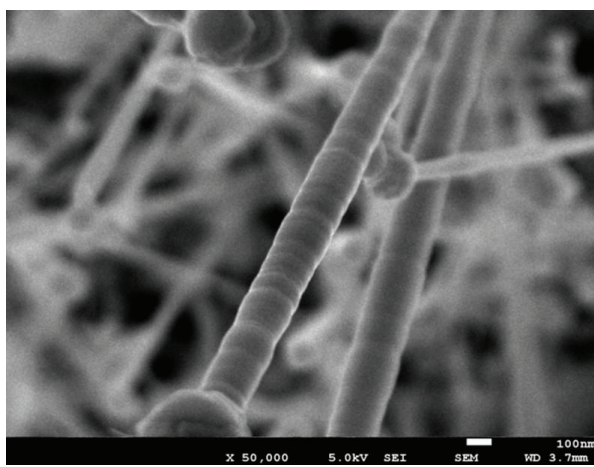

(a)

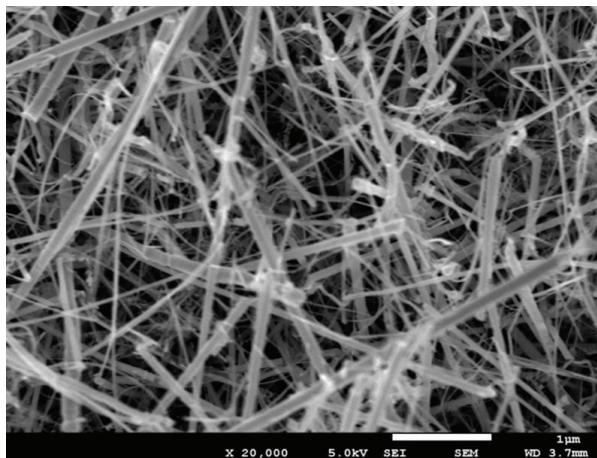

(c)

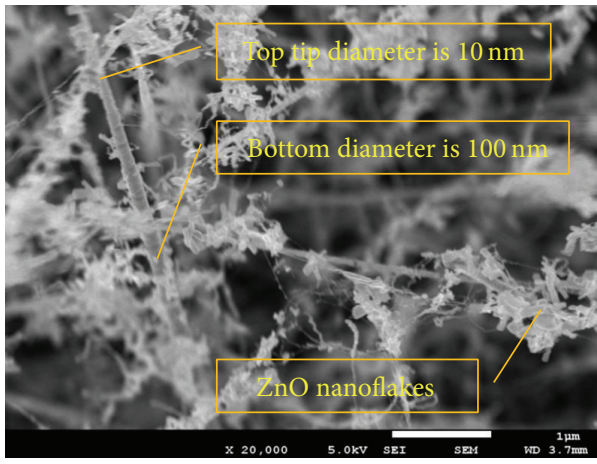

(e)

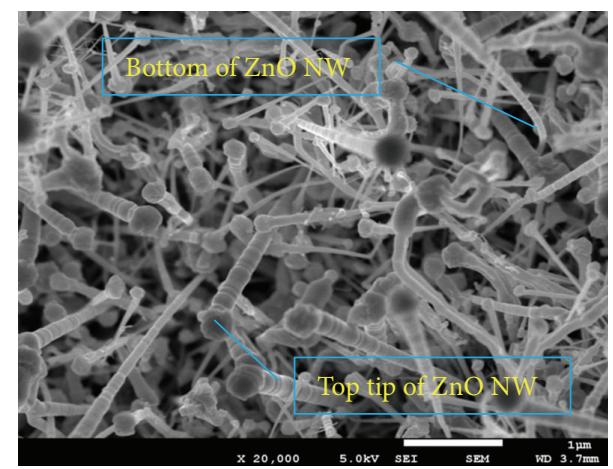

(b)

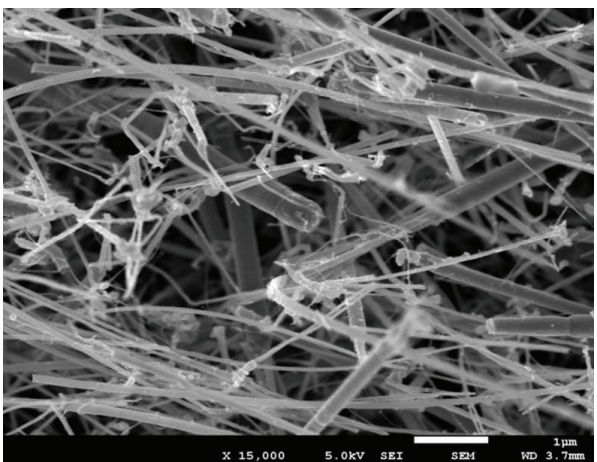

(d)

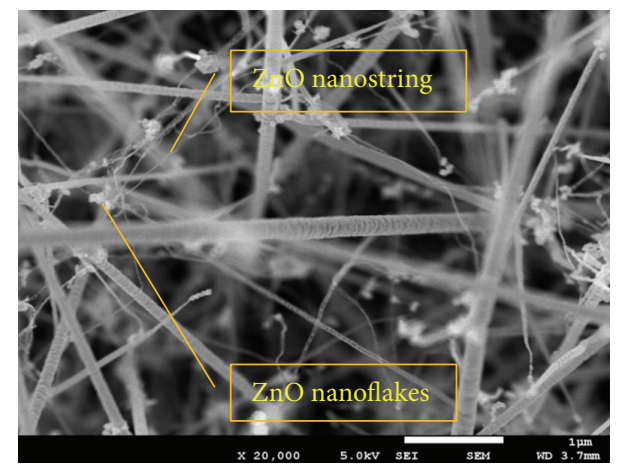

(f)

Figure 2: Images (a), (b), (c), (d), (e), and (f) are ZnO NWs prepared at deposition times of 5, 10, 15, 20, 25, and 30 minutes.

At growth times of 5 and 10 minutes, growth like button mushrooms are observable as shown in Figures 2(a) and 2(b). The diameters of the NWs ranged from $10 \mathrm{~nm}$ at the bottom to few hundred $\mathrm{nm}$ to the top tip and seem to be stacks of hexagonal $\mathrm{ZnO}$ plates in a single NW. The stacked hexagonal shape ZnO NWs are randomly orientated in long and straight dimension in whole direction on the Si substrate as seen in Figures 2(a) and 2(b).

Figures 2(c) and 2(d) are images of $\mathrm{ZnO}$ NWs produced for growth time of 15 and 20 minutes. They are also randomly orientated as long and straight NWs on Si substrate. The lengths are observed to be up to few microns greater than $\mathrm{ZnO}$ NWs prepared at growth times of 5 and 10 minutes. Their diameters ranged from 10 to $100 \mathrm{~nm}$. Besides that, formations of $\mathrm{ZnO}$ flakes are also observable in the $\mathrm{ZnO}$
NWs prepared at growth time of 20 minutes which could be an initial stage of formation of $\mathrm{ZnO}$ nanoflakes. More $\mathrm{ZnO}$ nanoflakes were observed to be around the NWs at growth times of 25 and 30 minutes. Tiny nanostrings also were grown connecting the $\mathrm{ZnO}$ nanoflakes as seen in Figure 2(f). However, the diameters ranged from $100 \mathrm{~nm}$ at the bottom to $10 \mathrm{~nm}$ to the top tip which looks like nanoneedles. This growth shape of $\mathrm{ZnO}$ nanoneedles is in opposition of $\mathrm{ZnO}$ NWs of 5 and 10 minutes growth time.

3.2. $X R D$. Figure 3 shows the XRD spectra of growth timedependent for $\mathrm{ZnO}$ NWs deposited on Si substrate in 5, 10, 15, 20, 25, and 30 minutes. The diffracted peaks attribute the polycrystalline nature of $\mathrm{ZnO}$ which can be indexed to the hexagonal wurtzite type $\mathrm{ZnO}$ (JCP2.2CA: 00-036-1451). 


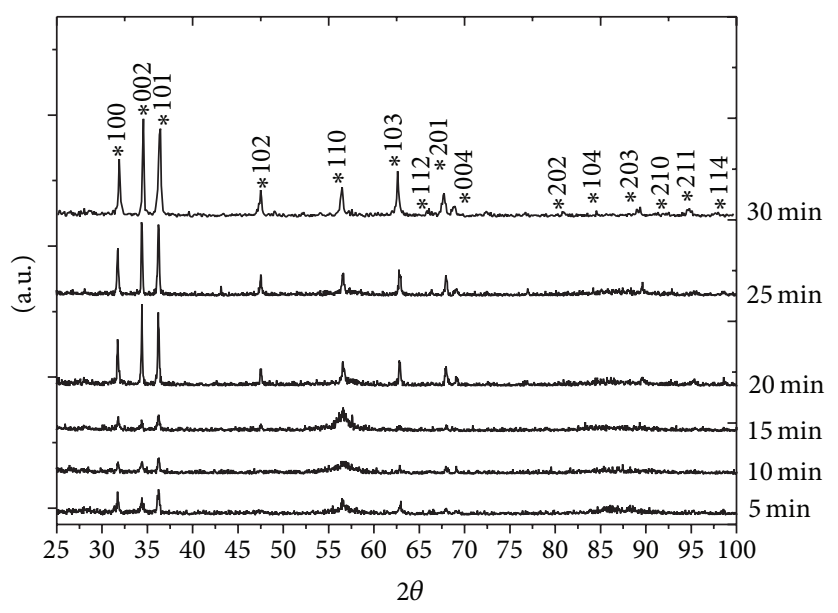

FiguRE 3: XRD spectra of ZnO NWs prepared at growth times of 5, 10, 15, 20, 25, and 30 minutes are stacked up.

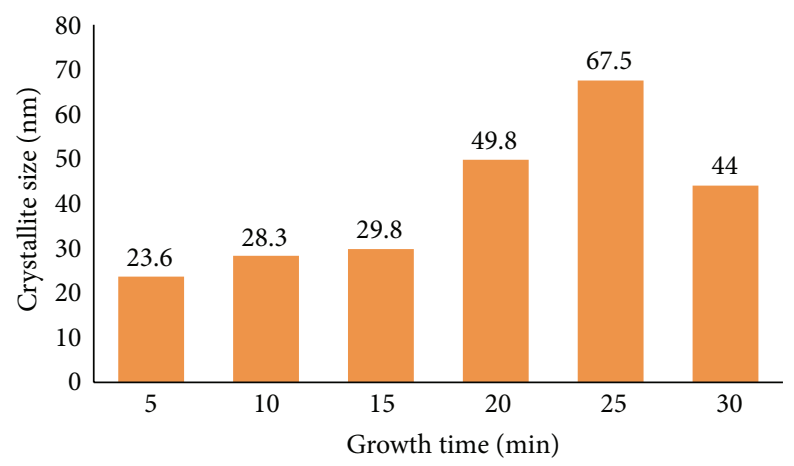

Figure 4: Crystallite size of $\mathrm{ZnO} /$ methanol NWs obtained at growth times of 5, 10, 15, 20, 25, and 30 minutes.

The prevalence of the peak that corresponds to (100) and (101) directions points to a preferential deposition time of 5,10 , and 15 minutes, whereas preferential growth direction in (002) plane is observable for growth times of 20,25, and 30 minutes. This may be due to the fact that there are no enough energized particles in the beginning of 5 to 15 minutes to move to low-energy sites that induced strain in the film. Significant contribution in the (100), (002), and (101) direction are noticeable when the deposition time is increased from 20 to 30 minutes but very slight preferential orientation is noticed in $\langle 002\rangle$ direction. This renders that more energized particles occupied the low energy sites in $c$-axis direction. Based on the preferential growth direction (002) with the increased deposition time, crystallite size $(D)$ of $\mathrm{ZnO}$ is calculated using Scherer formula [19]. The peak center of (002) from Gaussian deconvoluted shows slight shift to the left compared to the standard peak center $2 \theta$ of 34.422 of bulk $\mathrm{ZnO}(5.20661 \AA)$.
This indicates uniform tensile stress is distributed with higher calculated $d$ spacing value of $2.604 \AA$.

Table 1 shows that the calculated crystallite size has increased as the growth time was increased. Figure 4 shows distribution of crystallite size at growth times of 5 to 30 minutes. The crystallite size found to be increased at low rate during the growth time of 5, 10, and 15 minutes which could be due to formation of low energy site of lattice $\mathrm{ZnO}$. During 20,25 , and 30 minutes of growth time, the crystallite size dramatically increased to $49.8,67.5$, and $44.0 \mathrm{~nm}$, respectively. This could be condensation of energized particles such as $\mathrm{O}$ species onto the low energy site of $\mathrm{ZnO}$. At higher growth time, the density of growth of $\mathrm{ZnO}$ might have increased which could be due to condensation of more energized particles into NWs. The percentage of increment of crystallite size of $\mathrm{ZnO} \mathrm{NWs}$ is worked out for an increased deposition time of 5 minutes as shown below

$$
\begin{aligned}
& \text { increment of crystallie size: } \quad 17 \% \quad 5 \% \quad 40 \% \quad 35 \% \quad-34 \% \\
& \text { Deposition time: } 5 \longrightarrow 10 \longrightarrow 15 \longrightarrow 20 \longrightarrow 25 \longrightarrow 30 \text {. }
\end{aligned}
$$


TABLE 1: Details of ZnO NWs deposited at growth times of 5, 10, 15, 20, 25, and 30 minutes.

\begin{tabular}{|c|c|c|c|c|c|c|c|c|}
\hline \multirow{2}{*}{$\begin{array}{l}\text { Deposition time } \\
\text { (minutes) }\end{array}$} & \multirow{2}{*}{ Peak center $(2 \theta)(002)$} & \multirow{2}{*}{ Crystallite size, $D(\mathrm{~nm})$} & \multicolumn{2}{|c|}{$d$ spacing $(\AA)$} & \multicolumn{2}{|c|}{ Lattice parameter $(\AA)$} & \multirow{2}{*}{ Ratio $c / a$} & \multirow{2}{*}{ Volume $\left(\mathrm{nm}^{3}\right)$} \\
\hline & & & $(002)$ & (101) & $a$ & $c$ & & \\
\hline 5 & 34.388 & 23.6 & 2.60482 & 2.47700 & 3.25102 & 5.20960 & 1.6025 & 47.68 \\
\hline 10 & 34.380 & 28.3 & 2.60528 & 2.47562 & 3.24865 & 5.21082 & 1.6040 & 47.63 \\
\hline 15 & 34.390 & 29.8 & 2.60432 & 2.47619 & 3.24990 & 5.20933 & 1.6029 & 47.65 \\
\hline 20 & 34.393 & 49.8 & 2.60449 & 2.47642 & 3.25039 & 5.20893 & 1.6026 & 47.64 \\
\hline 25 & 34.396 & 67.5 & 2.60400 & 2.47684 & 3.25111 & 5.20846 & 1.6021 & 47.68 \\
\hline 30 & 34.387 & 44.0 & 2.60486 & 2.47667 & 3.25063 & 5.20972 & 1.6027 & 47.67 \\
\hline
\end{tabular}

We believe that high percentages of increment $17 \%, 40 \%$, $35 \%$, and $34 \%$ are identified for the increment of 5 minutes of deposition time from 5 to 10 minutes, 15 to 20 minutes, 20 to 25 minutes, and 25 to 30 minutes. This is due to the more energized particles that have occupied the low energy sites of the lattice of $\mathrm{ZnO}$ NWs, whereas low percentage of $5 \%$ for the increment of 5 minutes of deposition time from 10 to 15 minutes indicates that not enough energized particles occupied the lattice of $\mathrm{ZnO}$ NWs. The discernible change of growth percentage of $\mathrm{ZnO} \mathrm{NWs}$ explicates a sinusoidal growth trend whereby creation and occupancy of low energy sites simultaneously have taken place for each increment of 5 minutes deposition time. However, optimization in the growth time is noticed after 25 minutes of deposition.

3.3. Photoluminescence. PL study was carried out using Renishaw inVia Raman microscope at room temperature in the wavelength range from 350 to $800 \mathrm{~nm}$ using a $325 \mathrm{~nm}$ heliumcadmium (He-Cd) laser light which passes through three visible lens sets and a diffraction grating of 1200 lines/mm. The respective $\mathrm{PL}$ profile for $\mathrm{ZnO}$ NWs prepared at various growth times of $5,10,15,20,25$, and 30 minutes is shown in Figure 5. It is generally accepted that the surface states play a crucial role in PL spectra of $\mathrm{ZnO}$ nanomaterials [20]. Energy transition within the $\mathrm{ZnO}$ NWs and relationship between material color and defect structure were determined. The normalized PL shows a low near band-edge (NBE) emissions at $\sim 382 \mathrm{~nm}$, deep level (DL) emissions at $\sim 540 \mathrm{~nm}$, and near infrared (NIR) emissions at $\sim 765 \mathrm{~nm}$ for all the samples.

Figure 5 also indicates that the intensity of the emissions has decreased as the growth time was increased. The increased integral intensity of NBE emission indicates significant changes in the crystallinity of $\mathrm{ZnO} \mathrm{NWs}$ as well as the diameter of the NWs [21]. High crystallinity of $\mathrm{ZnO}$ is related to decrease of impurities and structural defects such as oxygen vacancy (Vo) and dislocations [22]. The decreased NBE also indicates rapid recombination of charge carriers in the defect energy states, which gives rise to intense DL emission as observed in Figure 5. The dependence of this DL emission on the growth times was analyzed to investigate the defect structure in $\mathrm{ZnO}$. In order to compare the relative contributions to the emissions Gaussian deconvoluted peaks were obtained for NBE, DL, and NIR and detailed in Table 2.

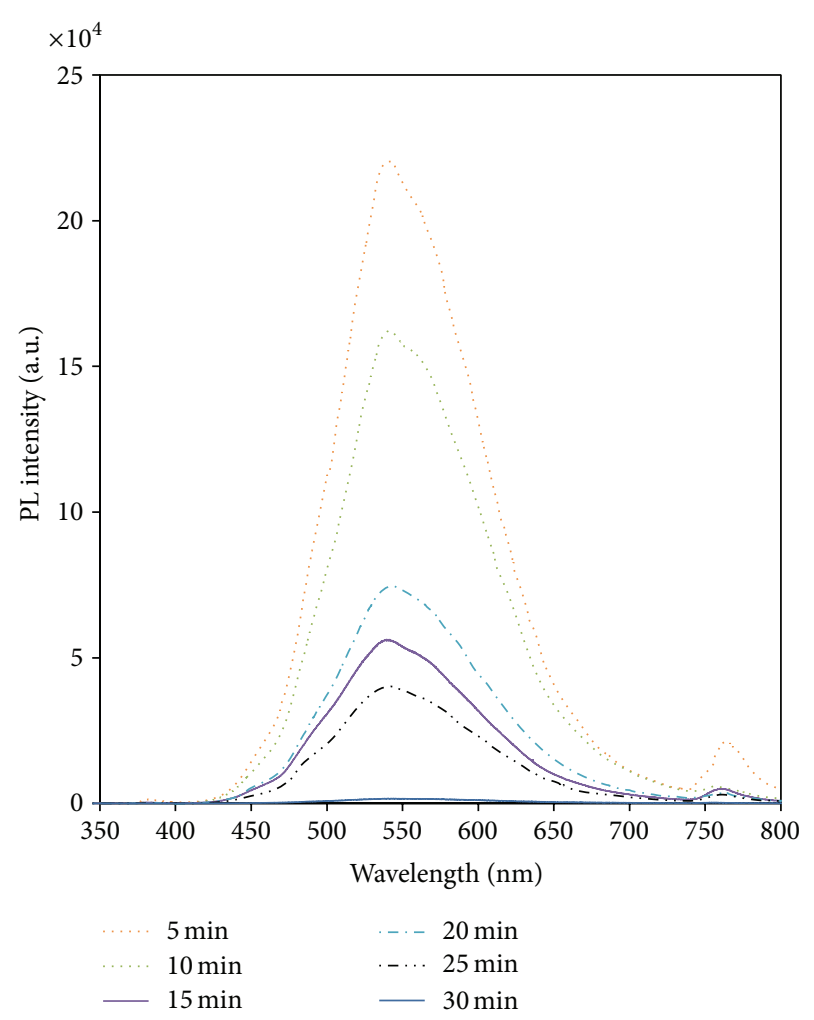

FIGURE 5: Photoluminescence profile of $\mathrm{ZnO}$ NWs deposited at various growth times of $5,10,15,20,25$, and 30 minutes.

Blue region around $460 \mathrm{~nm}(2.70 \mathrm{eV})$ can be linked to the presence of complexes of zinc interstitials $\left(\mathrm{Zn}_{\mathrm{i}}\right)$ [23].

The broad DLE green emissions at $\sim 540 \mathrm{~nm}(2.29 \mathrm{eV})$ can be related to oxygen vacancies (Vo) [20]. Halliburton et al. have shown that DL green emission is due to shallow donors or conduction band electrons [24]. Zhang et al. [25] and Patterson [26] have proved that Vo is an unlikely contributor to green emission compared to zinc vacancies $\left(\mathrm{V}_{\mathrm{Zn}}{ }^{2-}\right)$ based on the electron transition state. $\mathrm{V}_{\mathrm{Zn}}{ }^{2-}$ has the lowest formation energy in $\mathrm{O}$-rich conditions and in our experiment this is prevalent as the growth time was increased. The use of methanol environment provided excess oxygen for the $\mathrm{ZnO}$ formation reactions. Thus, $\mathrm{V}_{\mathrm{Zn}}{ }^{2-}$ is the most 


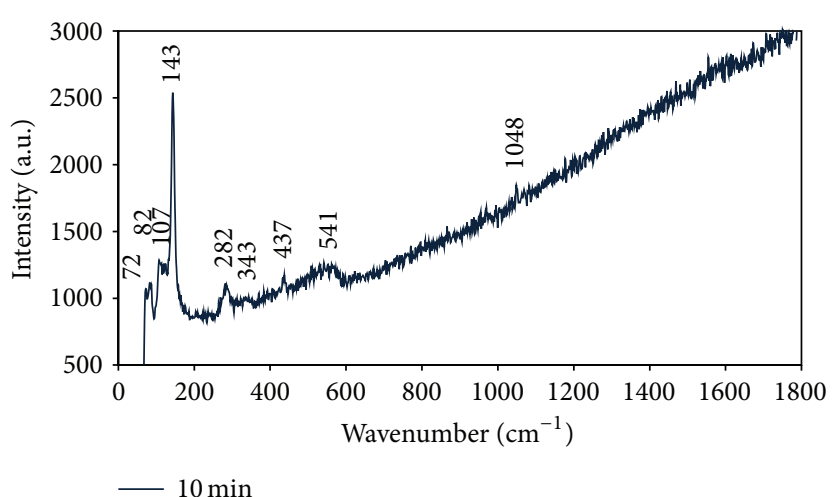

(a)

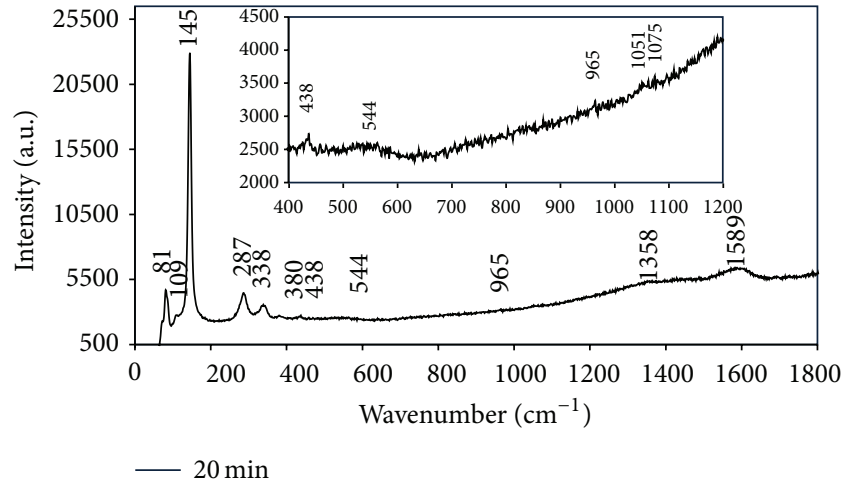

(b)

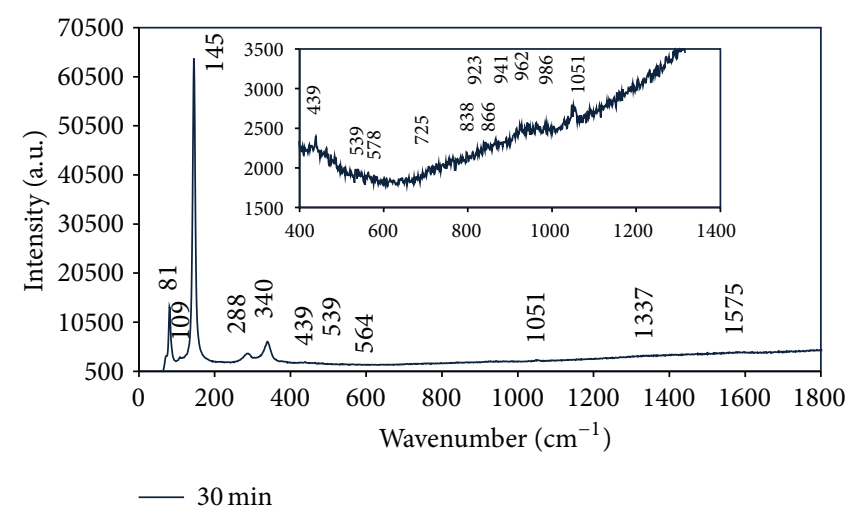

(c)

Figure 6: Raman scattering of ZnO NWs prepared at growth times of (a) 10, (b) 20, and (c) 30 minutes.

TABLE 2: Details of photoluminescence peaks of ZnO NWs near band edge, deep level, and infrared emissions obtained from Gaussian fits.

\begin{tabular}{lcccccc}
\hline $\begin{array}{l}\text { Deposition time } \\
\text { (minutes) }\end{array}$ & $\begin{array}{r}\text { NBE } \\
\text { Peak position }\left(\mathrm{cm}^{-1}\right)\end{array}$ & Energy $(\mathrm{eV})$ & $\begin{array}{c}\text { DL } \\
\text { Peak position }\left(\mathrm{cm}^{-1}\right)\end{array}$ & $\begin{array}{c}\text { NIR } \\
\text { Energy }(\mathrm{eV})\end{array}$ & $\begin{array}{c}\text { Peak position }\left(\mathrm{cm}^{-1}\right) \\
\text { Energy }(\mathrm{eV})\end{array}$ \\
\hline 5 minutes & 382 & 3.24 & 541 & 2.29 & 764 & 1.62 \\
10 minutes & 381 & 3.25 & 541 & 2.28 & 761 & 7.62 \\
15 minutes & 381 & 3.25 & 540 & 2.29 & 761 & 762 \\
20 minutes & 382 & 3.24 & 540 & 2.29 & 762 & 1.62 \\
25 minutes & 381 & 3.25 & 540 & 2.28 & 755 & 1.63 \\
30 minutes & 378 & 3.28 & 541 & & & 1.64 \\
\hline
\end{tabular}

energetically favorable and stable defects in the synthesized $\mathrm{ZnO}$ nanorods [25].

Small broad shoulder $\sim 560 \mathrm{~nm}(2.21 \mathrm{eV})$ indicates emissions of yellowish-green band from all $\mathrm{ZnO}$ NWs samples prepared at growth times of 5, 10, 15, 20, 25 and 30 minutes. This can be related to shallow donor $\mathrm{H}+$ defects in the $\mathrm{ZnO}$ nanorods which presents from the methanol solution [27]. $\mathrm{ZnO} \mathrm{NW}$ are believed to be a good candidate to study doping levels in $\mathrm{ZnO}$ nanostructures. The observed yellow luminescence at $\sim 560 \mathrm{~nm}(2.20 \mathrm{eV})$ is attributed to recombination of donors with acceptors from methanol solution believed to be $\mathrm{H}$ acceptors. Near infrared (NIR) luminescence $\sim 762 \mathrm{~nm}$ was observed in all $\mathrm{ZnO}$ samples except for sample prepared at growth time of 30 minutes which shows NIR at $755 \mathrm{~nm}$.
3.4. Raman Scattering. Figures 6(a), 6(b), and 6(c) show Raman spectrum of $\mathrm{ZnO}$ NWs which were prepared at growth times of 10,20, and 30 minutes. Dominant peak at $143 \mathrm{~cm}^{-1}$ is noticeable in $\mathrm{ZnO}$ NWs deposited at growth time of 10 minutes, whereas dominant peak at $145 \mathrm{~cm}^{-1}$ is observable in $\mathrm{ZnO} \mathrm{NWs}$ of growth times of 20 and 30 minutes. The intensity at $143 \mathrm{~cm}^{-1}$ was found to be enhanced as the growth time of $\mathrm{ZnO}$ NWs was increased by 10 minutes at constant substrate temperature of $800^{\circ} \mathrm{C}$. Cuscò et al. also have observed the same peak and have reported that intensity enhancement and sharpening of the peak at $142 \mathrm{~cm}^{-1}$ as Raman scattering was done at lower temperatures at $80 \mathrm{~K}$ due to local mode origin of the peak. This is in contradiction to our room temperatures Raman scattering [28]. 
Two peaks at lower wavenumber around 72 and $82 \mathrm{~cm}^{-1}$ were noticed in $\mathrm{ZnO}$ NWs of all samples. It is found to be peaks 72 and $82 \mathrm{~cm}^{-1}$ splitting from a single peak for lower growth time of 10 minutes. As the growth time was increased to 20 and 30 minutes peak at $72 \mathrm{~cm}^{-1}$ diminished and the peak at $82 \mathrm{~cm}^{-1}$ was found to be sharper. A research team from Germany has reported that this Raman peak at $82 \mathrm{~cm}^{-1}$ is related to bare $\mathrm{ZnO}$ nanoparticles obtained by decomposing $\mathrm{Zn}$ oximate in dimethyl formamide (DMF) [29]. The same group also has reported that Raman peak at $105 \mathrm{~cm}^{-1}$ can be assigned to $\mathrm{ZnO} / \mathrm{MWCNT}$ which is similar to peaks 107 and $109 \mathrm{~cm}^{-1}$ which were obtained in the sample of $\mathrm{ZnO} \mathrm{NWs}$ prepared for growth times of 10, 20, and 30 minutes. The similarity in observation attributes incorporation of carbon particles to $\mathrm{ZnO}$ NWs. The observed peaks at $\sim 82, \sim 109$, $\sim 143$, and $\sim 282 \mathrm{~cm}^{-1}$ which are below $300 \mathrm{~cm}^{-1}$ can be related to vibrations of $\mathrm{Zn}$ sublattice. Peak $282 \mathrm{~cm}^{-1}$ that has $\mathrm{A}_{1}$ symmetry can be assigned to $\mathrm{B}_{1}{ }^{\text {high }}-\mathrm{B}_{1}{ }^{\text {low }}$ mode. This peak was shifted to 287 and $288 \mathrm{~cm}^{-1}$ as the growth time increased to 20 and 30 minutes, respectively.

At the intermediate low frequency region the $\mathrm{E}_{2}$ high mode at 437,438 , and $439 \mathrm{~cm}^{-1}$ is noticeable, respectively, in samples prepared at growth times of 10, 20, and 30 minutes. These peaks were found to be sharper as the growth time was increased. This is an indication of $\mathrm{O}$ stoichiometry completion for longer growth time whereby $\mathrm{Zn}$ particles were bonded to O to form ZnO NWs. Peaks 343, 338, and $340 \mathrm{~cm}^{-1}$ which has $\mathrm{A}_{1}$ symmetry are observable, respectively, in $\mathrm{ZnO}$ NWs prepared at growth times of 10, 20, and 30 minutes. These modes are in good agreement with the difference between $\mathrm{E}_{2}$ high and $\mathrm{E}_{2}{ }^{\text {low }}$ frequencies. However, $343 \mathrm{~cm}^{-1}$ was observed to be broaden due to split up into 82 and $107 \mathrm{~cm}^{-1}$ frequency.

Peak at $380 \mathrm{~cm}^{-1}$ is observable only in $\mathrm{ZnO}$ NWs which was prepared in 20 minutes. This peak reflects $A_{1}(T O)$ mode measured to be in the room temperature Raman scattering. This contradicted to Cusco et al. of spectrum that has recorded the peak only at $80 \mathrm{~K}$ of Raman scattering. A broad band in region $500-600 \mathrm{~cm}^{-1}$ found to be diminished as the growth time was increased from 10 to 30 minutes. It is broadening with centered at $541 \mathrm{~cm}^{-1}$ for $\mathrm{ZnO} \mathrm{NWs}$ prepared at growth time of 10 minutes. This can be assigned to $\mathrm{A}_{1}$ symmetry and attributed to $2 \mathrm{~B}_{1}{ }^{\text {low }}$ and LA overtones along $\mathrm{L}, \mathrm{M}$, and $\mathrm{H}$ lines. As the broadening is diminished relatively to the increased growth time, extra peaks at 564 and $578 \mathrm{~cm}^{-1}$ were noticed. As in Figure 6(b) only one extra peak at $564 \mathrm{~cm}^{-1}$ is noticeable for $\mathrm{ZnO}$ NWs of 20 minutes while two peaks at 564 and $578 \mathrm{~cm}^{-1}$ are detectable for $\mathrm{ZnO} \mathrm{NWs}$ prepared at growth time of 30 minutes. Peak $564 \mathrm{~cm}^{-1}$ can be revealed to nonresonance Raman scattering, whereas $578 \mathrm{~cm}^{-1}$ which is close to $A_{1}(\mathrm{LO})$ mode has been reported by Ye et al. [30] in resonance Raman spectra of $\mathrm{ZnO}$ quantum dots. This peak in the proximity of $\mathrm{A}_{1}(\mathrm{LO})$ was assigned to surface optical modes predicted theoretically and $O$ vacancies, $\mathrm{Zn}$ interstitials, or combination of the two [31].

High frequency region from $820-1120 \mathrm{~cm}^{-1}$ has been reported that formed by optical overtones and combinations of TO and LO [32]. A weak peak at $1048 \mathrm{~cm}^{-1}$ which is observable in $\mathrm{ZnO} \mathrm{NWs}$ of 10 minutes can be assigned $\mathrm{TO}+\mathrm{LO}$ combination modes at the $\mathrm{A}$ and $\mathrm{H}$ points. As the growth time was increased to 20 and 30 minutes the peak has been shifted to right to $1051 \mathrm{~cm}^{-1}$. In sample $\mathrm{ZnO} \mathrm{NWs}$ of 30 minutes, the peak was found to be sharper with high intensity. Additionally, a peak at 1075 and $1090 \mathrm{~cm}^{-1}$ only on $\mathrm{ZnO}$ NWs of 20 and 30 minutes is noticeable. This peaks can be assigned to be $\mathrm{TO}+\mathrm{LO}$ combination modes at $\mathrm{M}$ and $\mathrm{L}$ points. ZnO NWs of 20 and 30 minutes of growth time show first order Raman absorption for the disordered bands D and G. A weak shoulder band D at 1358 and $1337 \mathrm{~cm}^{-1}$ was found in sample prepared at growth times of 20 and 30 minutes, respectively. The $\mathrm{G}$ band appeared to be broader compared to the $\mathrm{D}$ band. The $\mathrm{G}$ bands around 1589 and $1575 \mathrm{~cm}^{-1}$ are observable, respectively, in $\mathrm{ZnO}$ NWs of 20 and 30 minutes. As the growth time was increased from 20 to 30 minutes both the $D$ and $G$ bands were shifted to left. The presence of $D$ and $G$ band clearly indicated the presence of graphitic carbon in the sample. The $\mathrm{C}$ formed during the synthesis process was due to $C$ particles from methanol vapor.

3.5. TEM. The TEM images of the $\mathrm{ZnO} \mathrm{NWs}$ are shown in Figure 7. An assortment of nanostructures mainly NWs and nanoplates is observable in Figure 7(a). High resolution imaging of a selected NW in Figure 7(a), shown here in Figure 7(b), revealed clear crystal lattice fringes and the estimated distance between adjacent lattice planes was $0.26 \mathrm{~nm}$. This corresponded to the (0002) plane which indicated that the selected $\mathrm{ZnO}$ NWs were grown in the $c$-axis direction.

3.6. Growth Mechanism. A series of chemical mechanisms were proposed based on various outcomes that have been established elsewhere [33]. The thermally heated CuZn alloy has allowed only $\mathrm{Zn}$ atoms to escape as $\mathrm{Zn}$ vapors at temperatures greater than $395^{\circ} \mathrm{C}$ which then condensed into $\mathrm{Zn}$ solid on Si substrate. Here the presence of Ar environment believed has played an important role in changing the morphology of $\mathrm{Zn}$ film from large boundary to nanosized grain [34]. We also believe that the presence of Ar at $100 \mathrm{sccm}$ in the isolated system thermodynamically has rearranged and reduced the crystallite size of hexagonal $\mathrm{ZnO}$

$$
\mathrm{ZnCu} \text { (solid brass) } \stackrel{>395^{\circ} \mathrm{C}}{\longrightarrow} \mathrm{Zn} \text { (vapor) } \longrightarrow \mathrm{Zn} \text { film. }
$$

The growth of $\mathrm{ZnO}$ NWs in Figure 2 is obtained by allowing methanol vapor as Ar was flowed at $100 \mathrm{sccm}$ through the mixture of methanol and acetone solution via two-sided hollow $\mathrm{CuZn}$. We believed that $\mathrm{C}, \mathrm{H}$, and $\mathrm{O}$ atoms in methanol underwent a dehydrogenation process in the presence of $\mathrm{Cu}$ (in $\mathrm{CuZn}$ alloy) at $300^{\circ} \mathrm{C}$.

$$
\begin{aligned}
& \mathrm{CH}_{3} \mathrm{OH}_{(\mathrm{a})} \stackrel{\mathrm{Cu}, 300^{\circ} \mathrm{C}}{\longrightarrow} \mathrm{CH}_{3} \mathrm{O}_{(\mathrm{a})}+\mathrm{H}_{(\mathrm{a})} \\
& \mathrm{CH}_{3} \mathrm{O}_{(\mathrm{a})} \stackrel{\mathrm{Cu}, 300^{\circ} \mathrm{C}}{\longrightarrow} \mathrm{HCHO}_{(\mathrm{a})}+\mathrm{H}_{(\mathrm{a})} .
\end{aligned}
$$



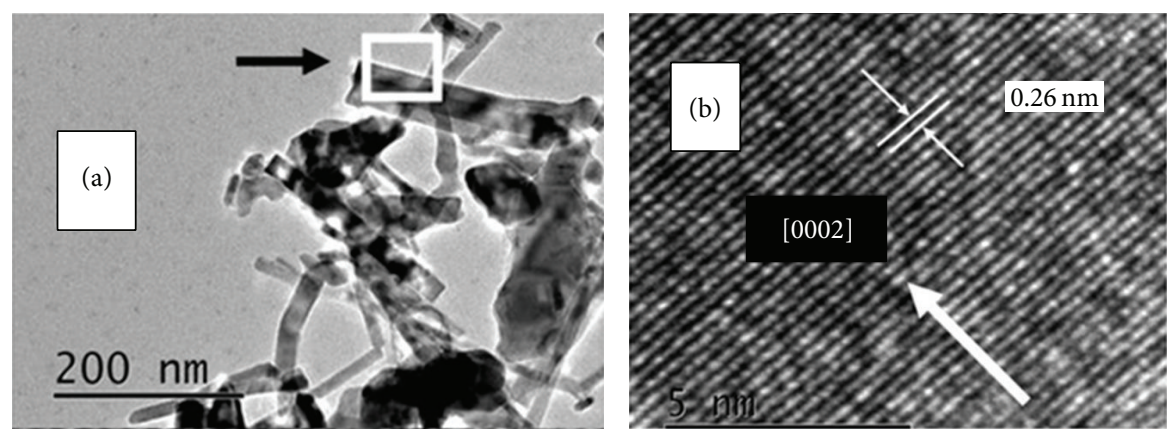

Figure 7: TEM images of ZnO NWs (a) at low resolution and (b) at high resolution.

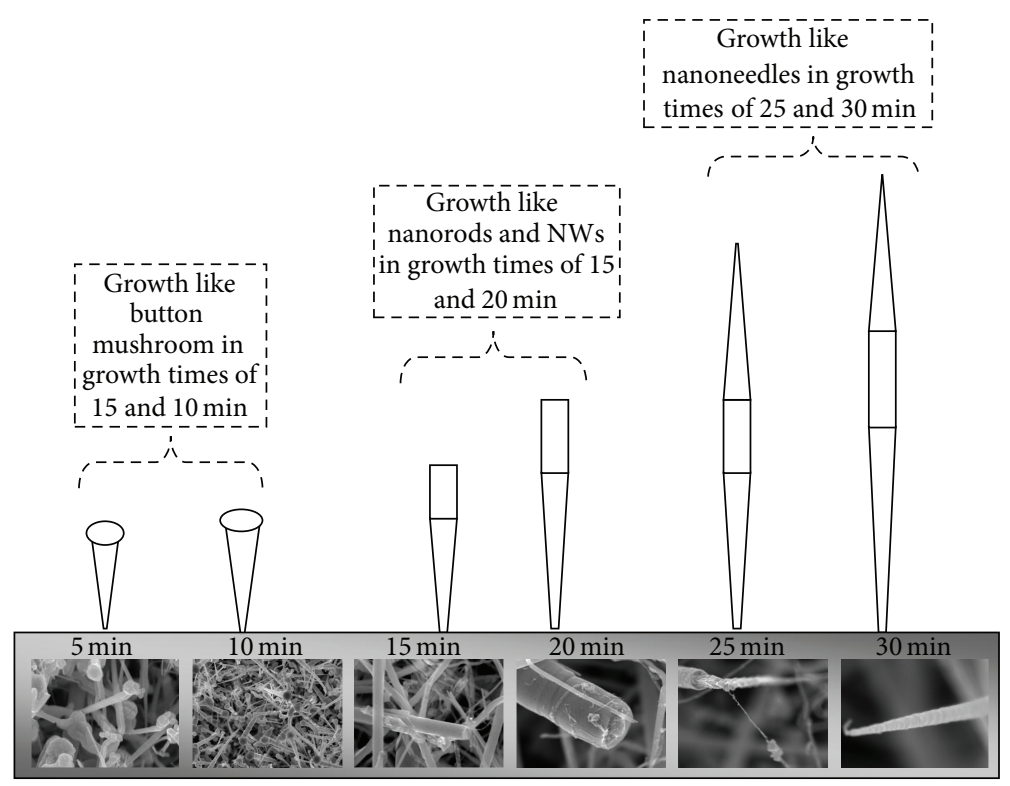

Figure 8: Predicted time dependent growth mechanism for $\mathrm{ZnO}$ NWs as growth time varies from 5 to 30 minutes.

Based on that, $\mathrm{Cu}$ in $\mathrm{CuZn}$ has acted as an catalyst and has oxidized the methanol vapor into an intermediate absorbable methoxy species $\left(\mathrm{CH}_{3} \mathrm{O}_{(\mathrm{a})}\right)$ and hydrogen atom $\left(\mathrm{H}_{(\mathrm{a})}\right)$ [35]. The $\mathrm{CH}_{3} \mathrm{O}_{(\mathrm{a})}$ is thermodynamically unstable and was readily converted to formaldehyde $(\mathrm{HCHO})$ by releasing a $\mathrm{H}_{(\mathrm{a})}$. The higher bond energy of $\mathrm{C}=\mathrm{O}$ in $\mathrm{HCHO}$ is thermodynamically unfavorable and the polarity of carbonyl group and its high basicity lowered the transition state energy of activation and therefore results in faster rate of reaction with readily presence species [36]. So the chemically unstable $\mathrm{HCHO}$ vapor easily reacts with $\mathrm{Zn}$ vapor or $\mathrm{Zn}$ atoms to that which have been thermally evaporated at temperatures above $395^{\circ} \mathrm{C}$ to form hexagonal $\mathrm{ZnO}$ NWs. Besides that, further oxidation of $\mathrm{HCHO}$ to $\mathrm{HCOOH}$ is not predicted due to $\mathrm{O}_{2}$ absence environment.

Apart from this, $\mathrm{C}-\mathrm{O}$ bond in $\mathrm{CH}_{3} \mathrm{O}_{(\mathrm{a})}$ was readily cleaved by $\mathrm{Zn}$ vapors [37]. Coadsorption of $\mathrm{O}_{(\mathrm{a})}$ and $\mathrm{Zn}_{(\mathrm{a})}$ appeared to give rise to reactive oxygen ions $\left(\mathrm{O}^{2-}\right)$ and $\mathrm{Zn}$ ions $\left(\mathrm{Zn}^{2+}\right)$ on the $\mathrm{Si}$ substrate. Thus $\mathrm{Zn}^{2+}$ ionically bonds with $\mathrm{O}^{2-}$ to form $\mathrm{ZnO}$ nanostructures

$$
\mathrm{CH}_{3} \mathrm{O}_{(\mathrm{a})} \longrightarrow \mathrm{O}_{(\mathrm{a})}+\mathrm{CH}_{3(\mathrm{a})}
$$

$$
\begin{gathered}
\mathrm{O}_{(\mathrm{a})}+2 \mathrm{e}^{-} \longrightarrow \mathrm{O}^{2-} \\
\mathrm{Zn}_{(\mathrm{a})}+\mathrm{O}^{2-} \longrightarrow \mathrm{ZnO} \text { (nanowires). }
\end{gathered}
$$

Based on the results and images of $\mathrm{ZnO}$ NWs prepared at different growth time of 5-30 minutes in steps of 5 minutes depicts controversial growth mechanisms that have not been reported elsewhere. Figure 8 shows an illustration of proposed growth mechanism. Structural transformation during the time-dependent growth of $\mathrm{ZnO}$ NWs has been taken into account. The shape has changed from button mushroom to NWs/nanorods and to nanoneedles as the growth time was increased from 5 minutes to 30 minutes. At growth time of 20 minutes growth of nanoneedles from a base of $\sim 150 \mathrm{~nm}$ diameter of $\mathrm{ZnO}$ is noticeable. A $\mathrm{ZnO}$ nanostring seems to be connected between the nanoneedle and $\mathrm{ZnO}$ flakes. At the growth time of 30 minutes formation of nanoneedles was observed to be in a cone shape.

\section{Conclusion}

VPT of methanol and thermal evaporation of CuZn assisted with hotwire is a feasible technique that can be utilized in 
synthesizing hexagonal $\mathrm{ZnO} \mathrm{NWs}$ in the laboratory. $\mathrm{ZnO}$ NWs in hexagonal shape is produced with crystalline size of $23.6 \mathrm{~nm}$ for growth time of 5 minutes. Formation of $\mathrm{ZnO}$ nanostrings and NWs was confirmed as the growth time was increased to 25 and 30 minutes. Calculated crystalline size shows independency on increased growth time where a drop in crystalline size after 25 minutes of growth period is noticeable. Although the intensity in the PL profile is inversely proportional to increased growth time $\mathrm{V}_{\mathrm{Zn}}{ }^{2-}$ is likely a contributor in the green emission region. Yellow emission region related recombination of donors to $\mathrm{H}+$ defects sides. Blue region around $460 \mathrm{~nm}(2.70 \mathrm{eV})$ confirmed presence of complexes of $\mathrm{Zn}_{\mathrm{i}}$. Raman peaks also confirmed decoration of the wall of $\mathrm{ZnO} N W$ s with $\mathrm{C}$ particles from methanol. Interlattice spacing of $0.26 \mathrm{~nm}$ showed growth of $\mathrm{ZnO}$ NWs in (0002) direction.

In future studies the $\mathrm{ZnO}$ NWs produced using other aliphatic alcohols can be considered promising material in future applications. This is due to possible functionalization on $\mathrm{ZnO}$ NWs using $\mathrm{C}$ source materials.

\section{Conflict of Interests}

The authors declare that there is no conflict of interests regarding the publication of this paper.

\section{Acknowledgment}

This work is supported by Peruntukan Penyelidikan Pascasiswazah (PPP) of University Malaya Grant no. PS212/2009A and UMRG Grant no. RG247-12AFR.

\section{References}

[1] C. Jagadish and S. J. Pearton, Zinc Oxide Bulk, Thin Films, and Nanostructures: Processing, Properties, and Applications, Elsevier, Amsterdam, The Netherlands, 2006.

[2] M. Guo, P. Diao, and S. M. Cai, "Photoelectrochemical properties of highly oriented $\mathrm{ZnO}$ nanotube array films on ITO substrates," Chinese Chemical Letters, vol. 15, no. 9, pp. 1113-1116, 2004.

[3] R. D. Piner, J. Zhu, F. Xu, S. Hong, and C. A. Mirkin, “'Dip-pen’ nanolithography," Science, vol. 283, no. 5402, pp. 661-663, 1999.

[4] G. Y. Yi, C. Wang, and W. I. Park, "ZnO nanorods: synthesis, characterization and applications," Semiconductor Science and Technology, vol. 20, supplement 4, pp. S22-S34, 2005.

[5] Z. Lockman, Y. Pet Fong, T. Wai Kian, K. Ibrahim, and K. A. Razak, "Formation of self-aligned $\mathrm{ZnO}$ nanorods in aqueous solution," Journal of Alloys and Compounds, vol. 493, no. 1-2, pp. 699-706, 2010.

[6] C. S. Lao, J. Liu, P. Gao et al., " $\mathrm{ZnO}$ nanobelt/nanowire schottky diodes formed by dielectrophoresis alignment across au electrodes," Nano Letters, vol. 6, no. 2, pp. 263-266, 2006.

[7] S. Kim, M. C. Jeong, B. Y. Oh, W. Lee, and J. M. Myoung, "Fabrication of $\mathrm{Zn} / \mathrm{ZnO}$ nanocables through thermal oxidation of Zn nanowires grown by RF magnetron sputtering," Journal of Crystal Growth, vol. 290, no. 2, pp. 485-489, 2006.

[8] L. Wang, K. Chen, and L. Dong, "Synthesis of exotic zigzag ZnO nanoribbons and their optical, electrical properties," Journal of Physical Chemistry C, vol. 114, no. 41, pp. 17358-17361, 2010.
[9] W. Ouyang and J. Zhu, "Catalyst-free synthesis of macro-scale $\mathrm{ZnO}$ nanonail arrays on Si substrate by simple physical vapor deposition," Materials Letters, vol. 62, no. 17-18, pp. 2557-2560, 2008.

[10] S. L. Wang, X. Jia, P. Jiang, H. Fang, and W. H. Tang, "Largescale preparation of chestnut-like $\mathrm{ZnO}$ and $\mathrm{Zn}-\mathrm{ZnO}$ hollow nanostructures by chemical vapor deposition," Journal of Alloys and Compounds, vol. 502, no. 1, pp. 118-122, 2010.

[11] Q. J. Feng, L. Z. Hu, H. W. Liang et al., "Catalyst-free growth of well-aligned arsenic-doped $\mathrm{ZnO}$ nanowires by chemical vapor deposition method," Applied Surface Science, vol. 257, no. 3, pp. 1084-1087, 2010

[12] P. Tonto, O. Mekasuwandumrong, S. Phatanasri, V. Pavarajarn, and P. Praserthdam, "Preparation of $\mathrm{ZnO}$ nanorod by solvothermal reaction of zinc acetate in various alcohols," Ceramics International, vol. 34, no. 1, pp. 57-62, 2008.

[13] Y. S. Lim, J. W. Park, S.-T. Hong, and J. Kim, "Carbothermal synthesis of $\mathrm{ZnO}$ nanocomb structure," Materials Science and Engineering B: Solid-State Materials for Advanced Technology, vol. 129, no. 1-3, pp. 100-103, 2006.

[14] C. Jia, Y. Chen, G. Liu, X. Liu, S. Yang, and Z. Wang, "Growth of c-oriented $\mathrm{ZnO}$ films on (0 01$) \mathrm{SrTiO} 3$ substrates by MOCVD," Journal of Crystal Growth, vol. 311, no. 1, pp. 200-204, 2008.

[15] A. Wagner, A. Behrends, A. Waag, and A. Bakin, "Two step deposition method with a high growth rate for $\mathrm{ZnO}$ nanowire arrays and its application in photovoltaics," Thin Solid Films, vol. 520, no. 14, pp. 4637-4641, 2012.

[16] D. Yu, T. Trad, J. T. McLeskey Jr., V. Craciun, and C. R. Taylor, "ZnO nanowires synthesized by vapor phase transport deposition on transparent oxide substrates," Nanoscale Research Letters, vol. 5, no. 8, pp. 1333-1339, 2010.

[17] Z. Zhu, T.-L. Chen, Y. Gu, J. Warren, and R. M. Osgood Jr., "Zinc oxide nanowires grown by vapor-phase transport using selected metal catalysts: a comparative study," Chemistry of Materials, vol. 17, no. 16, pp. 4227-4234, 2005.

[18] A. Baruj, P. A. Larochette, S. Sommadossi, and H. E. Troiani, "Surface phase transformation induced by the dezincification of a beta $\mathrm{Cu}-\mathrm{Zn}$ alloy on highly deformed systems," Applied Surface Science, vol. 254, no. 1, pp. 72-75, 2007.

[19] X. L. Chen, X. H. Geng, J. M. Xue, D. K. Zhang, G. F. Hou, and Y. Zhao, "Temperature-dependent growth of zinc oxide thin films grown by metal organic chemical vapor deposition," Journal of Crystal Growth, vol. 296, no. 1, pp. 43-50, 2006.

[20] K. Vanheusden, W. L. Warren, C. H. Seager, D. R. Tallant, J. A. Voigt, and B. E. Gnade, "Mechanisms behind green photoluminescence in $\mathrm{ZnO}$ phosphor powders," Journal of Applied Physics, vol. 79, no. 10, pp. 7983-7990, 1996.

[21] M. H. Huang, Y. Wu, H. Feick, N. Tran, E. Weber, and P. Yang, "Catalytic growth of zinc oxide nanowires by vapor transport," Advanced Materials, vol. 13, no. 2, pp. 113-116, 2001.

[22] D. M. Bagnall, Y. F. Chen, Z. Zhu, T. Yao, M. Y. Shen, and T. Goto, "High temperature excitonic stimulated emission from ZnO epitaxial layers," Applied Physics Letters, vol. 73, no. 8, pp. 1038-1040, 1998.

[23] D. C. Look, G. C. Farlow, P. Reunchan, S. Limpijumnong, S. B. Zhang, and K. Nordlund, "Evidence for native-defect donors in n-type ZnO," Physical Review Letters, vol. 95, no. 22, Article ID 225502, pp. 2-4, 2005.

[24] L. E. Halliburton, N. C. Giles, N. Y. Garces et al., "Production of native donors in $\mathrm{ZnO}$ by annealing at high temperature in $\mathrm{Zn}$ vapor," Applied Physics Letters, vol. 87, no. 17, Article ID 172108, pp. 1-3, 2005. 
[25] S. Zhang, S.-H. Wei, and A. Zunger, "Intrinsic $n$-type versus $p$ type doping asymmetry and the defect physics of ZnO," Physical Review B, vol. 63, Article ID 075205, pp. 1-7, 2001.

[26] C. Patterson, "Role of defects in ferromagnetism in Zn1xCoxO: a hybrid density-functional study," Physical Review B, vol. 74, Article ID 144432, pp. 1-13, 2006.

[27] C. G. van de Walle, "Hydrogen as a doping cause in $\mathrm{ZnO,"}$ Physical Review Letters, vol. 85, pp. 1012-1015, 2000.

[28] R. Cuscò, E. Alarcón-Lladó, J. Ibáñez et al., "Temperature dependence of Raman scattering in ZnO," Physical Review B, vol. 75, Article ID 165202, pp. 1-11, 2007.

[29] J. Khanderi, R. C. Hoffmann, A. Gurlo, and J. J. Schneider, "Synthesis and sensoric response of $\mathrm{ZnO}$ decorated carbon nanotubes," Journal of Materials Chemistry, vol. 19, no. 28, pp. 5039-5046, 2009.

[30] J. D. Ye, S. Tripathy, F. Ren, X. W. Sun, G. Q. Lo, and K. L. Teo, "Raman-active Fröhlich optical phonon mode in arsenic implanted ZnO," Applied Physics Letters, vol. 94, no. 1, Article ID 011913, pp. 1-3, 2009.

[31] S. Baskoutas, P. Giabouranis, S. N. Yannopoulos et al., "Preparation of $\mathrm{ZnO}$ nanoparticles by thermal decomposition of zinc alginate," Thin Solid Films, vol. 515, no. 24, pp. 8461-8464, 2007.

[32] J. Serrano, A. H. Romero, F. J. Manjón, R. Lauck, M. Cardona, and A. Rubio, "Pressure dependence of the lattice dynamics of ZnO: an ab initio approach," Physical Review B-Condensed Matter and Materials Physics, vol. 69, no. 9, Article ID 94306, pp. 1-14, 2004.

[33] L. S. Panchakarla, A. Govindaraj, and C. N. R. Rao, "Formation of $\mathrm{ZnO}$ nanoparticles by the reaction of zinc metal with aliphatic alcohols," Journal of Cluster Science, vol. 18, no. 3, pp. 660-670, 2007.

[34] H. Lv, D. D. Sang, H. D. Li, X. B. Du, D. M. Li, and G. T. Zou, "Thermal evaporation synthesis and properties of $\mathrm{ZnO}$ nano/microstructures using carbon group elements as the reducing agents," Nanoscale Research Letters, vol. 5, no. 3, pp. 620-624, 2010.

[35] A. K. Chen and R. Masel, "Direct conversion of methanol to formaldehyde in the absence of oxygen on $\mathrm{Cu}(210)$," Surface Science, vol. 343, no. 1-2, pp. 17-23, 1995.

[36] P. Y. Bruice, Organic Chemistry, 5th edition, 2006.

[37] K. R. Harikumar and C. N. R. Rao, "Role of oxygen transients in the facile scission of $\mathrm{C}-\mathrm{O}$ bonds of alcohols on $\mathrm{Zn}$ surfaces," Chemical Communications, no. 4, pp. 341-342, 1999. 

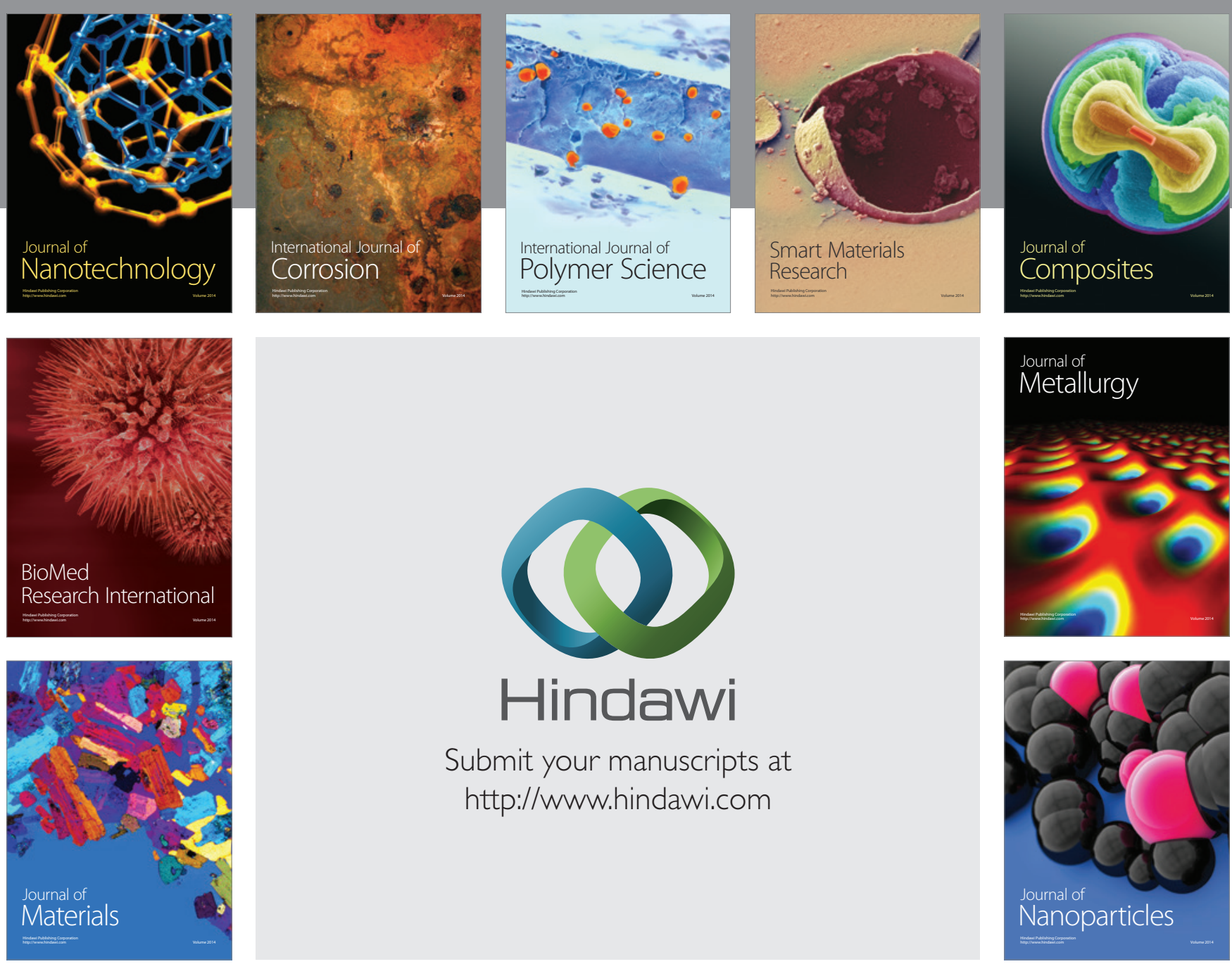

Submit your manuscripts at http://www.hindawi.com
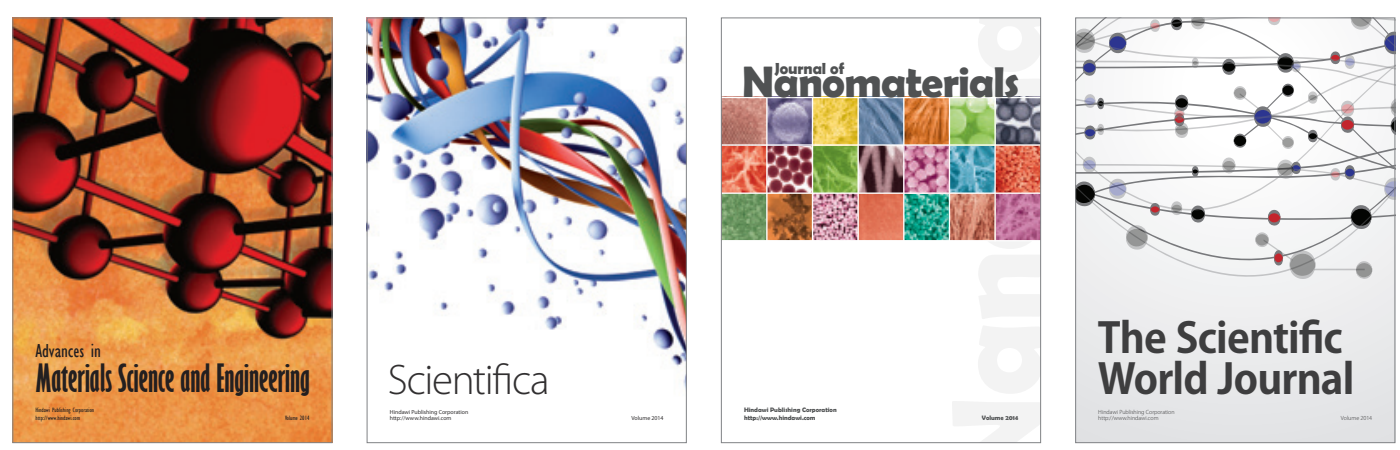

\section{The Scientific World Journal}
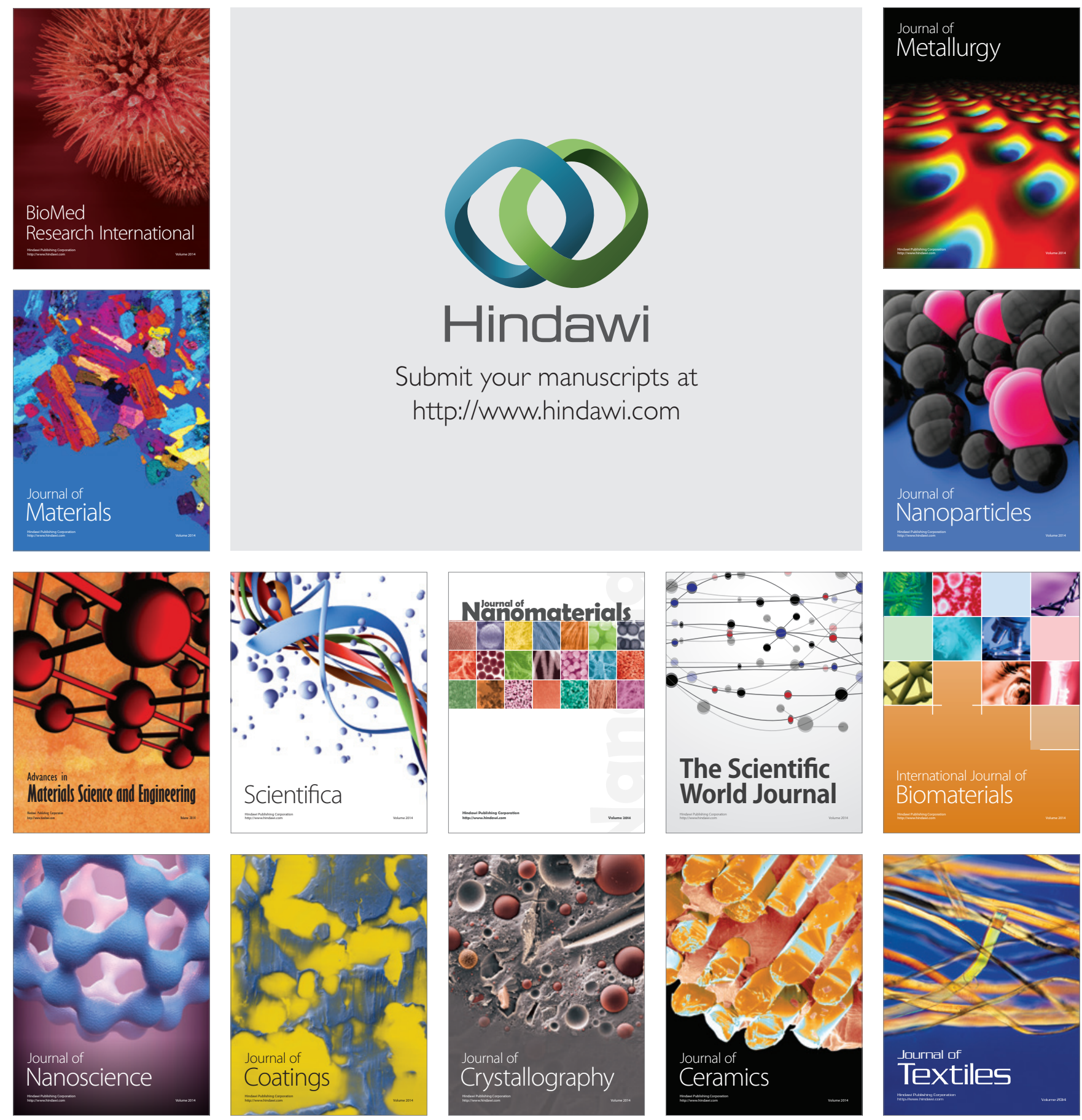